\title{
Solar Control in Buildings with Large Glazed Surfaces: The Role of Internal Screens
}

\author{
Antonio Carbonari, and Scarpa M. \\ Università IUAV di Venezia, Venezia, Italy
}

\begin{abstract}
A large part of new office buildings is characterized by extended external glazed surfaces, generally located without any care about orientation. Without a suitable solar control strategy, this fact implies a series of well-known problems: high-energy demand and consequent carbon dioxide emissions for HVAC, as well as thermal and luminous discomfort. Moreover, if the working room is large, the values of physical parameters influencing comfort are relevantly variable from point to point. The best way to control entering solar radiation is based on the use of external movable elements, such as slats or screens. However, in some winter periods, it would be appreciated to promote the collection of solar radiation in order to contribute to cover heating loads. In this case, the use of internal diffusing or redirecting elements (i.e., blinds or venetian curtains) is necessary to avoid glare phenomena. The physical properties of these elements influence the room thermal balance, and their temperatures influence indoor thermal comfort conditions, particularly for the nearest occupants. This work tries to identify, by means of computer simulations, optimal physical properties of some kinds of internal diffusing screens. A case study has been examined: it consists in a medium size office room.
\end{abstract}

Key words: design tool, energy demand, comfort

\section{Introduction}

Office buildings characterised by large glazed envelope surfaces are increasingly spreading. The presence of glass reduces the energy consumption related to artificial lighting but even more increases the energy demand for heating ventilation and air conditioning (HVAC). In fact, even in temperate climates, a room with a South oriented glazed wall may require cooling loads also during the winter, due to the combined effect of solar and internal heat gains, whereas, in absence of a sufficient solar radiation, the glazed wall in the cold period causes high heating loads. For the same reasons, other orientations can present alternatively relevant heating and cooling loads depending on the time and season.

Corresponding author: Antonio Carbonari, Assistant Professor, research areas/interests: building energy and solar radiation, energy and luminous aspects. E-mail: carbonar@iuav.it.
The control of the entering solar radiation is the first step to limit primary energy demand and related $\mathrm{CO}_{2}$ emissions in this kind of buildings.

For this purpose, internal shading, diffusing or redirecting elements (i.e., blinds or venetian curtains) are less efficient than the external ones (referring in particular to movable slats), but they are provided with a simpler frame, requiring lower embodied energy and lower costs of maintenance.

However, also in presence of external devices, the use of internal elements can be necessary. In fact, in some heating periods, it is helpful to take advantage of the solar radiation in the amount contributing to cover the heating loads. In this case, when direct solar radiation is not completely stopped by external devices or when a big part of a luminous sky is visible, the use of internal elements may avoid glare phenomena and thermal discomfort due to direct radiation impinging over the occupants. The physical properties of these elements influence room thermal balance, as well as 
the indoor thermal comfort conditions, particularly for the occupants nearest to the glazed surface.

In previous works $[1,2]$, external devices were examined, whereas the present work focuses on the internal ones and in particular on diffusing screens.

This work is aimed at identifying their optimum physical properties in order to ensure the indoor comfort conditions and limit primary energy demand for HVAC and lighting.

A further aim consists in the formulation of design recommendations aimed at integrating diffusing screens into complex dynamic solar control devices.

\section{Methods}

This work was carried out by means of computer simulations, by using software Ener_Lux. This software, already described in previous works [1, 2], is mainly aimed at the study of solar control devices and related operating strategies. It allows simultaneous analyses of energy as well as thermal and luminous comfort aspects. Therefore it takes into account the physical system composed by a room, one glazed opening, internal and external solar control devices (such as slats, blinds, overhangs and any element casting shadows onto the opening) as well as the surrounding urban environment, including the building containing the room under investigation.

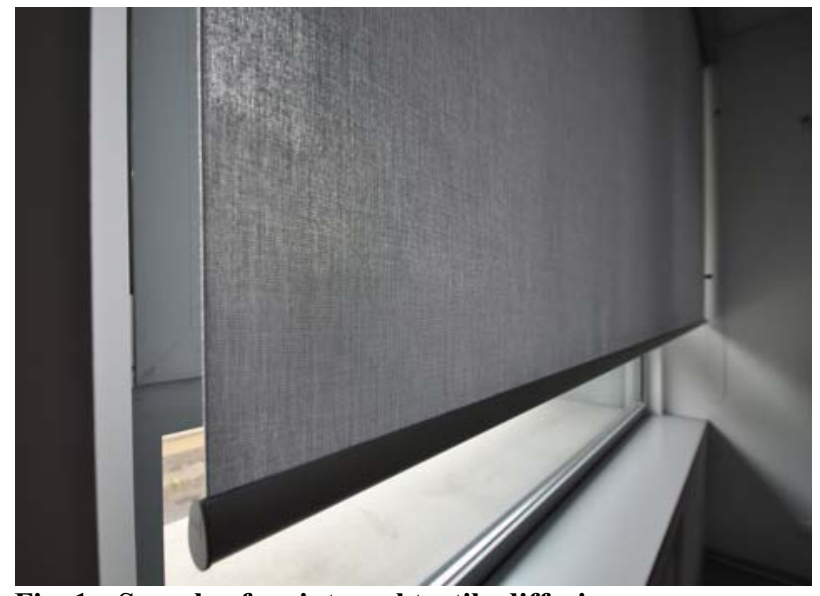

Fig. 1 Sample of an internal textile diffusing screen.

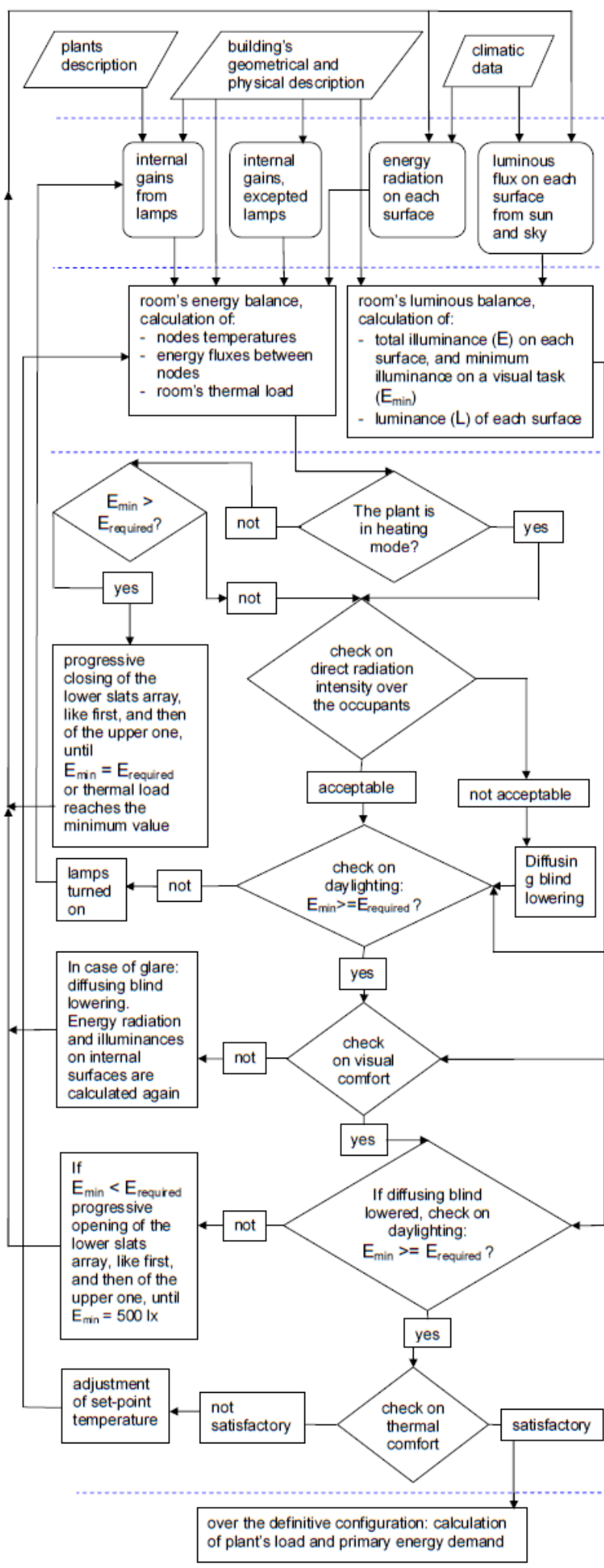

Fig. 2 Scheme of the Ener_Lux calculation flow. The figure shows the behaviour of the program when referring to a double slat array provided with mirror-like surfaces in the upper section. 
All the calculations of Ener_Lux are performed with hourly step. The program calculates: room sensible and latent thermal loads, primary energy demand for HVAC and artificial lighting, values of the main indices used to evaluate thermal and visual comfort. In particular Predicted Mean Vote (PMV) and Predicted Percentage of Dissatisfied (PPD) [3, 4] are used to evaluate thermal comfort.

To obtain these results it executes the energy balance of the room. The related algorithm is based on a finite difference method and on the heat balance of elementary zones, in a thermal grid model.

The balance takes into account the solar radiation impinging on each exposed surface, coming from sun, sky $[5,6]$ and mutual reflections between surfaces.

In a similar way, with regard to the luminous field, the program calculates illuminance values on each surface as the sum of components coming from the sun, sky [7] and mutual reflections between surfaces. If the illuminance value for a specific visual task is not sufficient it is assumed that the lighting system is activated and the consequent heat flow is included in the room heat balance. It is possible to take into account the system zoning and lighting control by dimmers.

When the daylighting is sufficient, an algorithm simulating the occupant's visual field is used to evaluate the corresponding visual comfort (as shown in Figs. 3 and 4).

Different kinds of glare are considered:

- veiling glare due to direct radiation impinging on the visual task, which can imply thermal discomfort too, since the radiation hits the occupant as well,

- glare due to large luminous sources (typically the sky seen through the windows or directly illuminated surfaces), that is evaluated by the Daylighting Glare Index (DGI) [8], or to small but very luminous light sources, that is evaluated by Unified Glare Index (UGR) [9].
When adjustable devices are simulated, all the solar control actions aimed at maintaining thermal and luminous comfort, such as slats tilting or screen lowering, are automatically simulated: in such cases, the program modifies the solar control device configuration and repeats the simulation of the hourly time-step. The check about visual discomfort conditions is performed only when the lamps are turned off.

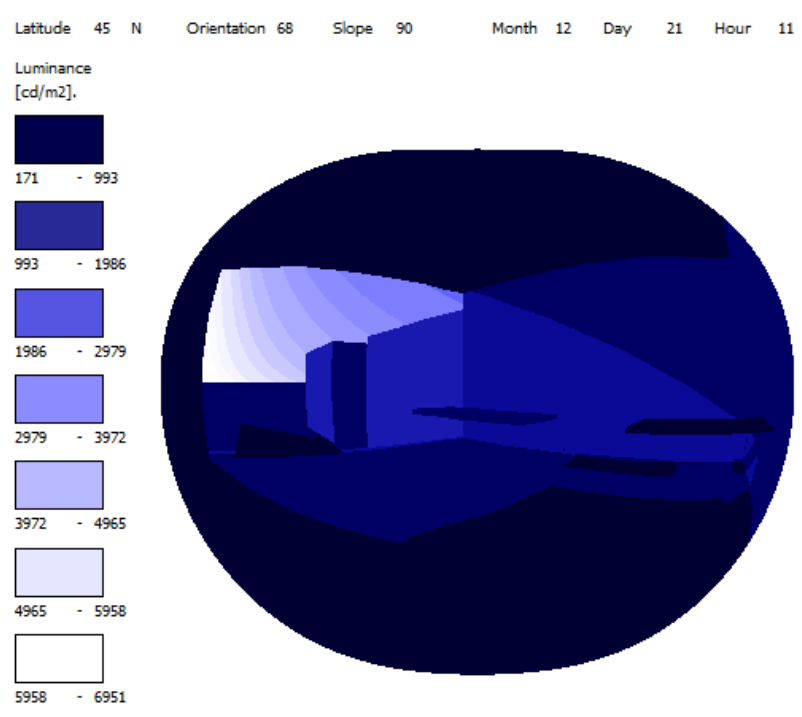

Fig. 3 Simulation of an occupant's visual field aimed at luminous comfort assessment. In this case, solar control devices are not present.

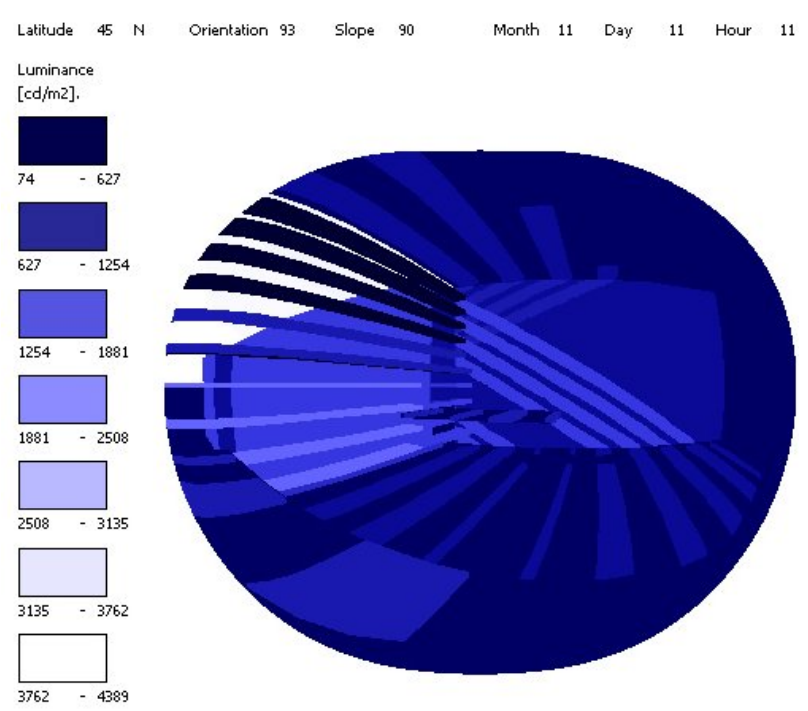

Fig. 4 Simulation of an occupant's visual field in presence of a double array of tiltable slats, whose upper part has mirror like finishing. 
In case of thermal discomfort, averaged in the room as a whole, the program modifies progressively the indoor air set-point temperature repeating the hourly time-step calculation until the comfort conditions are obtained.

The program allows the user to perform the simulation of different indoor environment control parameters: not only air temperature but operative temperature $\left(\mathrm{t}_{\mathrm{o}}\right)$ and Predicted Mean Vote (PMV) too. Whereas devices controlling $t_{0}$ or PMV are actually unusual, this kind of control is executed by occupants when the manual adjustment of HVAC terminals is available.

\section{The Case Study}

The case study consists in an office room of medium size: $5.88 \mathrm{~m}$ wide along the façade, $6.18 \mathrm{~m}$ deep orthogonally to the façade, and with net height equal to $3.27 \mathrm{~m}$. The room is located in an office building of the industrial district of Venice (Marghera).

The building exhibits an entirely glazed façade almost South oriented (with $22^{\circ}$ West azimuth). In the local climate this orientation is the least favorable during the cooling period. This façade is now equipped with a system of tiltable slats incorporating PV cells, as shown in Fig. 5. On this side of the building, a representative room at the second floor was chosen. The building structure is composed by reinforced concrete. Internal walls consist in hollow bricks $0.08 \mathrm{~m}$ thick, with $0.02 \mathrm{~m}$ thick plaster layers on both the sides. Floors consist in hollow bricks and reinforced concrete: $0.24 \mathrm{~m}$ is the construction thickness, plus $0.06 \mathrm{~m}$ of screed and flooring and $0.02 \mathrm{~m}$ of plaster in the lower part. The only external surface of the room is the glazed one, composed by a double glazing of $0.006 \mathrm{~m}$ glass layers, and a $0.012 \mathrm{~m}$ air gap (overall $\mathrm{U}$ value: 2 $\left.\mathrm{W} \cdot \mathrm{m}^{-2} \cdot \mathrm{K}^{-1}\right)$. All the other internal enclosing surfaces are considered as adiabatic.

The internal gains consist of: sensible and latent thermal flow from occupants ( $65 \mathrm{~W}$ of sensible thermal power and $65 \mathrm{~W}$ latent power per occupant), office devices (one computer for each occupant and one shared printer for a time averaged total power equal to $75 \mathrm{~W}$ per occupant) and fluorescent lamps (luminous efficacy: $91 \mathrm{~lm} / \mathrm{W}$, total power: $732 \mathrm{~W}$ ).

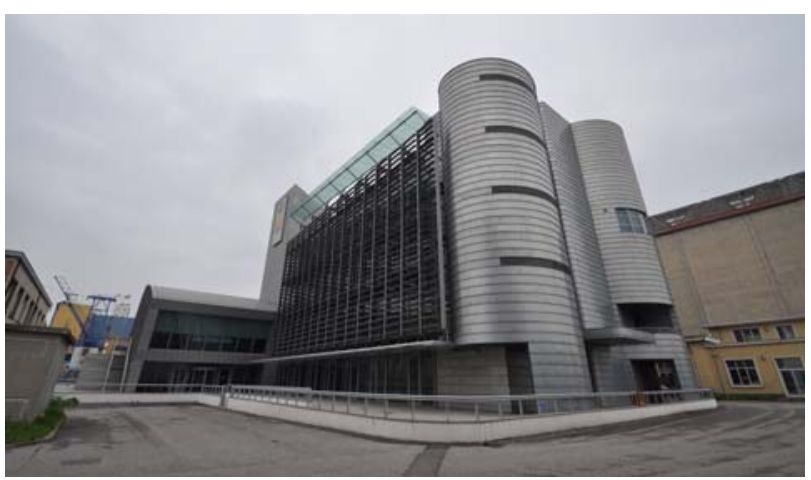

Fig. 5 The examined building.
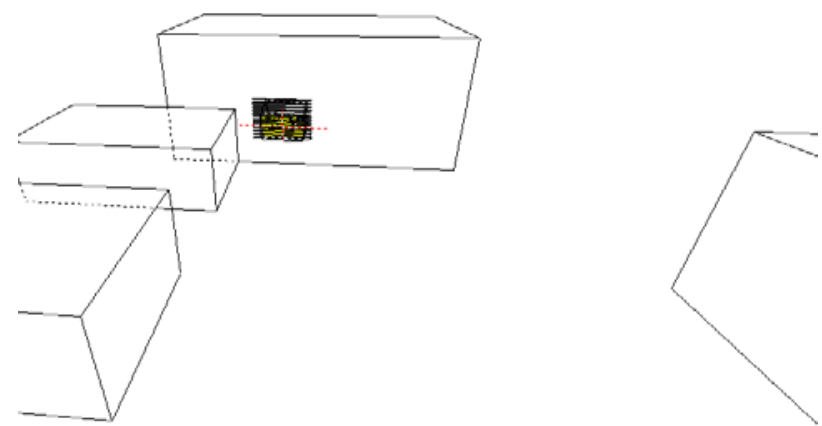

Fig. 6 Geometrical model of the physical domain, the building containing the examined room in the background.

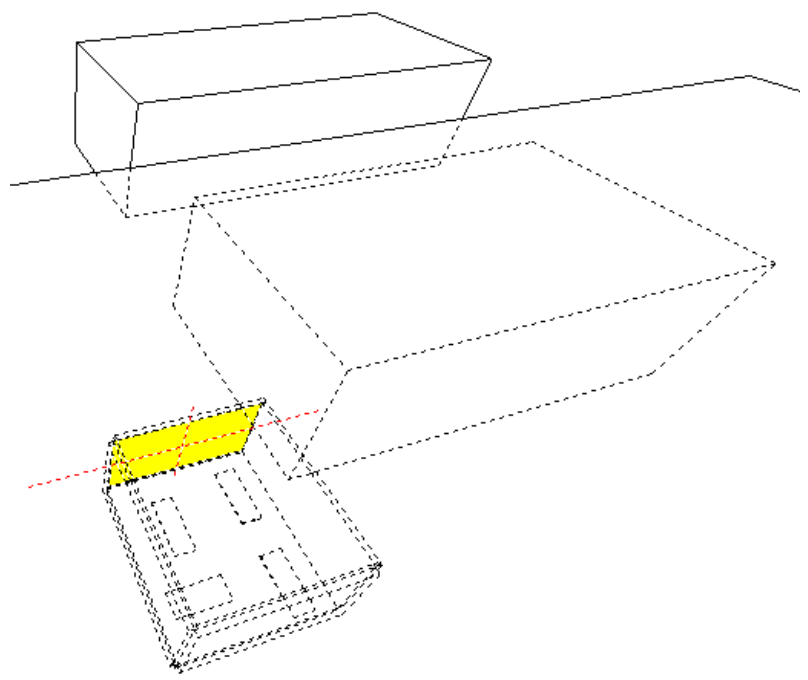

Fig. 7 Geometrical model of the physical domain, with possible workplaces positions inside the room, and the glazed surface in yellow. 
At first, the presence of four occupants was assumed, but in this case, because of the sum of solar and internal heat gains, the room exhibited only cooling loads, except in the early hours of some winter mornings. Then, the number of occupants was reduced down to two, with the aim to explore the behavior of the diffusing devices also in presence of heating loads.

To assess the visual comfort, four possible positions were considered, at different distances from the glazed surface. For each position, the worst line of sight was

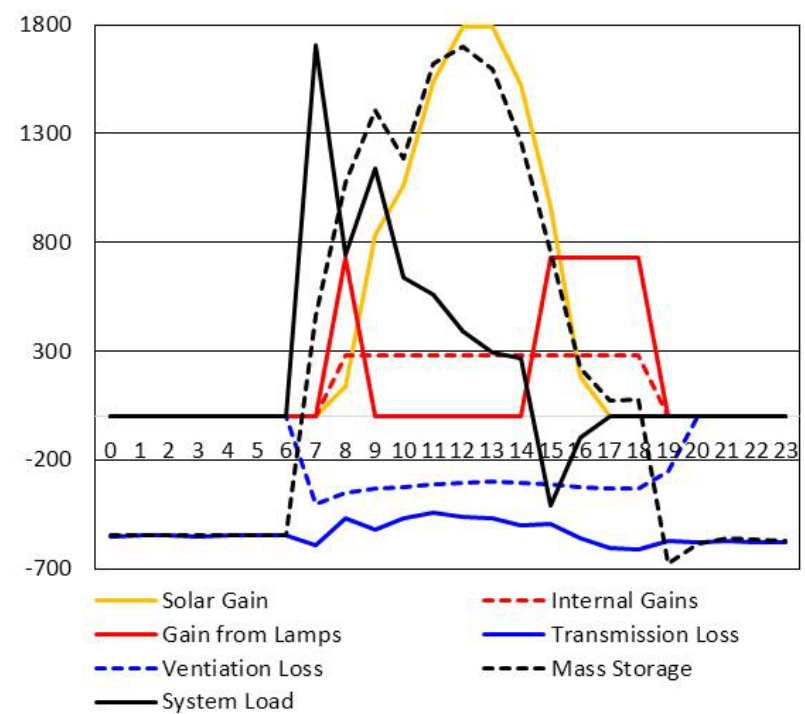

Fig. 8 Textile screen. Room sensible heat flows [W] along a day in the heating period (January, 21st)

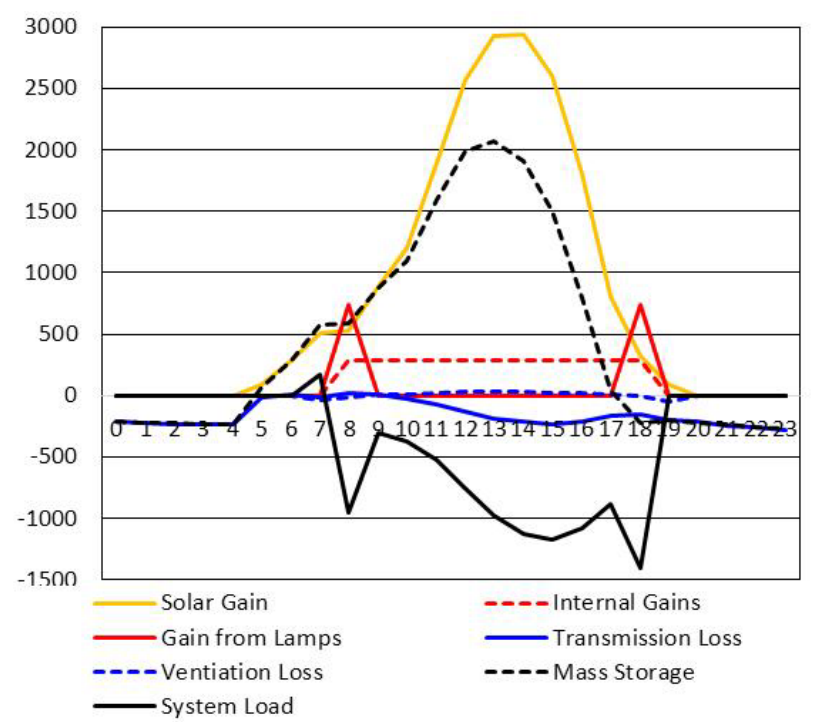

Fig. 9 Textile screen. Room's sensible heat flows [W] in a day of cooling period (July 21). considered, i.e., the one implying the higher contrast in luminance values within the visual field. Thus, the glazed surface must be present in it, but it is empirically assumed that it cannot occupy more than half of the visual field, otherwise occupants eyes may adapt to the luminance of the external landscape.

To calculate the primary energy demand related to HVAC, the room was assumed provided with a full-air centralized loop, and the daily occupancy time is from 09:00 (but the system is switched on one hour before) to 19:00. It was assumed that the warm fluid was provided by a gas-boiler and the cold fluid by an electrically driven chiller (vapor compression chiller). The indoor set-point temperatures were assumed equal to $20^{\circ} \mathrm{C}$ in winter and $26^{\circ} \mathrm{C}$ in summer, as recommended by the related Italian standard, whereas during mid-seasons it was assumed equal to the daily average outdoor air dry bulb temperature, because the clothing of the occupants is adapted to it. The relative humidity set-point is assumed equal to $50 \%$ all over the year.

\section{The Examined Solar Control Devices}

The internal diffusing screen is lowered when internal discomfort conditions are detected, such as in the case of glare or strong direct radiation over the occupants. In this work, the following kinds of screens are considered [10]:

- heavy textile blind,

- micro-perforated unpolished steel sheet,

- micro-perforated polished aluminium sheet,

- micro-perforated steel sheet, polished only on the external side (hereinafter named "steel 2").

The behaviour of the various screens was compared at first assuming no external slats; then the results related to the most convenient among them (i.e., the textile blind) were compared with the ones of two configurations including the same screen and an external array of tiltable slats. In the first configuration the slats are packable, whereas in the second one the slats are not packable. 
Table 1 Physical Properties of the Examined Screens

\begin{tabular}{|c|c|c|c|c|c|c|c|c|c|c|}
\hline Material & $\begin{array}{c}\rho \\
{\left[\mathrm{kg} / \mathrm{m}^{3}\right]}\end{array}$ & $\begin{array}{c}\lambda \\
{[\mathrm{W} /(\mathrm{m} \cdot \mathrm{K})]}\end{array}$ & $\begin{array}{c}\mathrm{C} \\
{\left[\mathrm{W} /\left(\mathrm{m}^{2} \cdot \mathrm{K}\right)\right]}\end{array}$ & $\begin{array}{c}\mathrm{M} \\
{\left[\mathrm{kg} / \mathrm{m}^{2}\right]}\end{array}$ & $\begin{array}{c}\mathrm{c} \\
{\left[\mathrm{kJ} /\left(\mathrm{m}^{2} \cdot \mathrm{K}\right)\right]}\end{array}$ & $\begin{array}{l}\mathrm{r}_{\mathrm{se}} \\
{[-]}\end{array}$ & $\begin{array}{l}\mathrm{r}_{\mathrm{vi}} \\
{[-]}\end{array}$ & $\begin{array}{l}\alpha_{\mathrm{s}} \\
{[-]}\end{array}$ & $\begin{array}{c}\varepsilon_{\mathrm{e}} \\
{[-]}\end{array}$ & $\begin{array}{c}\varepsilon_{\mathrm{i}} \\
{[-]}\end{array}$ \\
\hline Textile & 600 & 0.035 & 20 & 0.30 & 0.30 & 0.425 & 0.425 & 0.1 & 0.960 & 0.960 \\
\hline Steel & 7800 & 52 & 104000 & 2.34 & 7.76 & 0.157 & 0.157 & 0.4 & 0.480 & 0.480 \\
\hline Aluminium & 2700 & 209 & 418000 & 0.81 & 1.20 & 0.400 & 0.400 & 0.1 & 0.015 & 0.015 \\
\hline Steel 2 & 7800 & 52 & 104000 & 2.34 & 7.76 & 0.157 & 0.157 & 0.4 & 0.015 & 0.480 \\
\hline
\end{tabular}

In order to focus the analysis towards thermal and radiative properties of the materials, the same thickness (equal to $0.5 \mathrm{~mm}$ ) and the same coefficient of solar transmission $\tau_{\mathrm{s}}$ (equal to 0.5 ) were assumed for all the examined screens.

The solar transmission coefficient $\left(\tau_{\mathrm{s}}\right)$ is referred to the total solar spectrum and does not include the infrared (IR) radiation re-emitted by the screen, which is calculated apart, as a function of the screen temperature. Consequently, the solar transmission coefficient assumes the same value as the luminous transmission coefficient $\left(\tau_{\mathrm{v}}\right)$.

The solar radiation absorbed by the screen is calculated as the difference between the transmitted and the reflected radiation.

The values of reflection and absorption coefficients and infrared (IR) emissivity are averaged on the frontal gross surface. Therefore, in case of micro-perforated sheets, these values are approximately equal to fifty percent of the ones referred to the uniform surfaces.

The other relevant physical properties of the screens are resumed in Table 1, where the meaning of the symbols is the following:

$\rho:$ density $\left[\mathrm{kg} / \mathrm{m}^{3}\right]$;

$\lambda$ : thermal conductivity $[\mathrm{W} /(\mathrm{m} \cdot \mathrm{K})]$;

$\mathrm{C}$ : thermal conductance $\left[\mathrm{W} /\left(\mathrm{m}^{2} \cdot \mathrm{K}\right)\right]$;

$\mathrm{m}$ : frontal mass density $\left[\mathrm{kg} / \mathrm{m}^{2}\right]$;

c: thermal capacity referred to the unit of surface area $\left[\mathrm{kJ} /\left(\mathrm{m}^{2} \cdot \mathrm{K}\right)\right]$;

$\mathrm{r}_{\mathrm{se}}$ : external side reflection coefficient (reflectance) for solar radiation;

$\mathrm{r}_{\mathrm{vi}}$ : internal side reflection coefficient for visible radiation;

$\alpha_{s}$ : external side absorption coefficient for total solar radiation;

$\varepsilon_{\mathrm{e}}$ : external side IR emissivity; $\varepsilon_{\mathrm{i}}$ : internal side IR emissivity.

\section{Results}

\subsection{Screens and Internal Surface Temperatures}

It was assumed that all the examined screens halve the solar radiation entering the room, whereas the fraction of solar radiation absorbed and reflected are different for each kind of screen. These physical properties influence the room thermal balance, and the screen temperature influences indoor thermal comfort conditions, particularly for the nearest occupants.

The textile screen achieves the lowest temperatures when exposed to solar radiation, because of its high solar reflection coefficient (0.425) and high IR emissivity values (0.96). These characteristics, during the winter, cause proportionally high heat loss towards the glass and hence to the outdoor environment (see Figs. 10 and 11). In fact, in the winter, this is the only screen colder than the indoor air and surfaces.

Screens in aluminium and steel reach higher temperatures values. The aluminium screen presents the same high reflection coefficient as the textile one, but a lower IR emissivity on both sides. Consequently, in a long period in the year (i.e., except in the coldest period) it reaches a temperature slightly lower than the one of the steel screen, as shown in Figs. 12 and 13. Its heat exchange with the indoor air is similar, but the external losses and IR transmission towards the indoor surfaces are lower, consequently, internal surfaces temperatures are close to the ones obtained with textile screen, as shown in Fig. 15. 


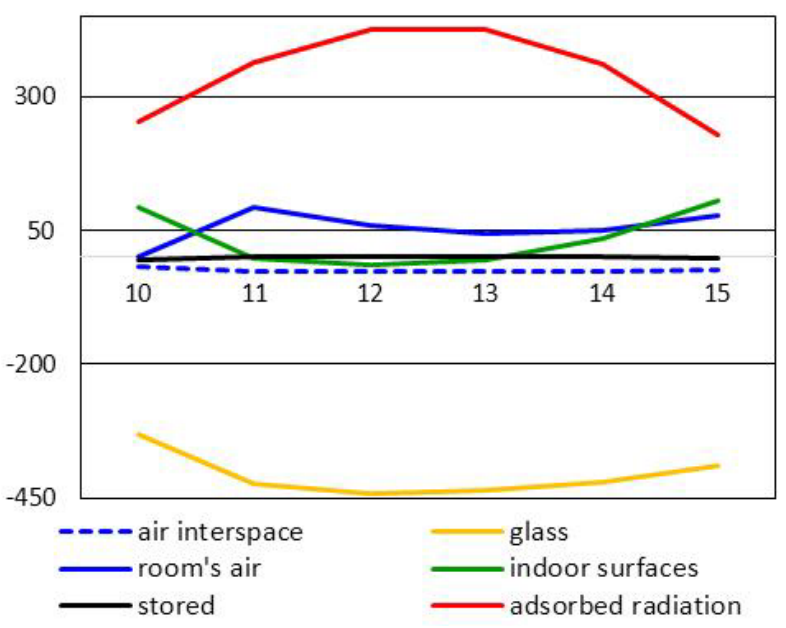

Fig. 10 January 21st, heat flows exchanged by the textile screen with the connected nodes of the thermal grid [W].

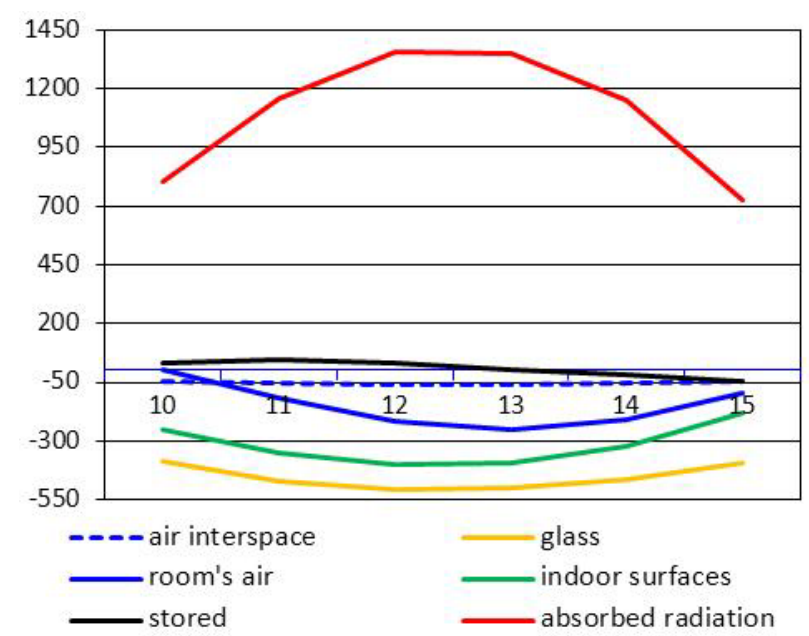

Fig. 11 January 21st, heat flows exchanged by the steel screen with the connected nodes of the thermal grid [W].

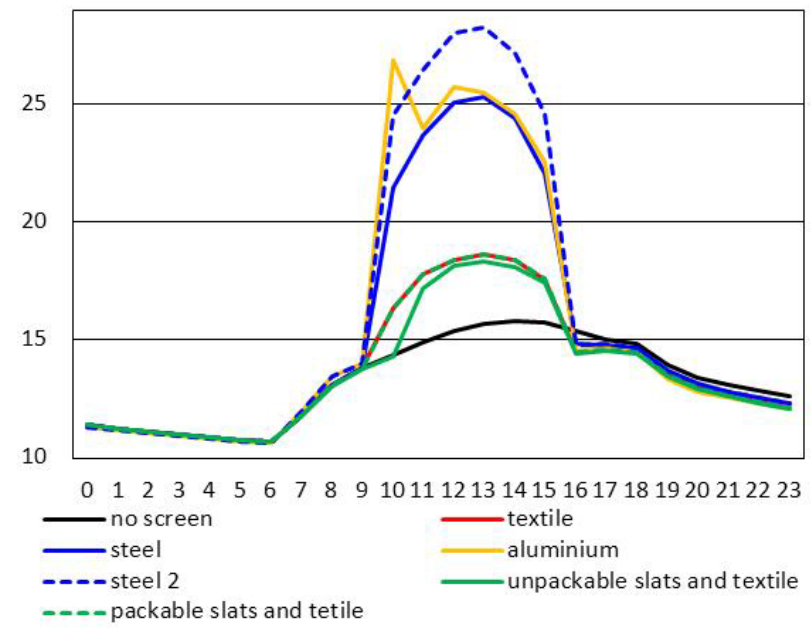

Fig. 12 January 21st, window internal surface (glass or screen) temperature values $\left[{ }^{\circ} \mathrm{C}\right]$.

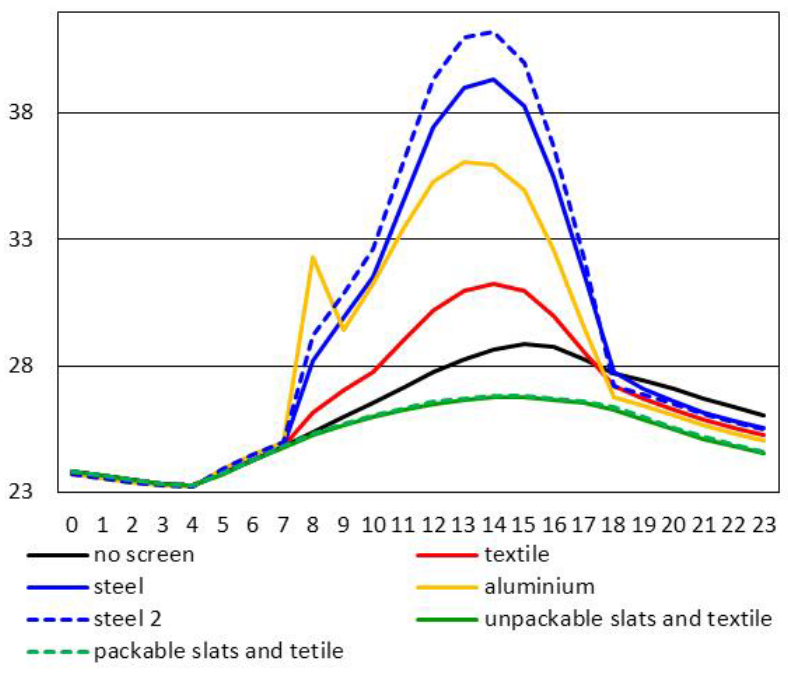

Fig. 13 July 21st, window internal surface (glass or screen) temperature values $\left[{ }^{\circ} \mathrm{C}\right]$.

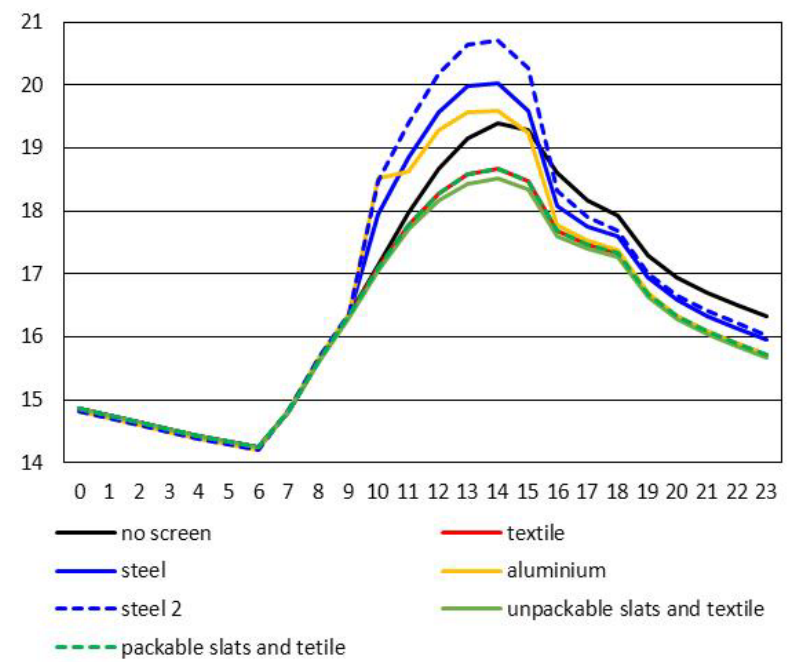

Fig. 14 January 21st, room MRT values $\left[{ }^{\circ} \mathrm{C}\right]$.

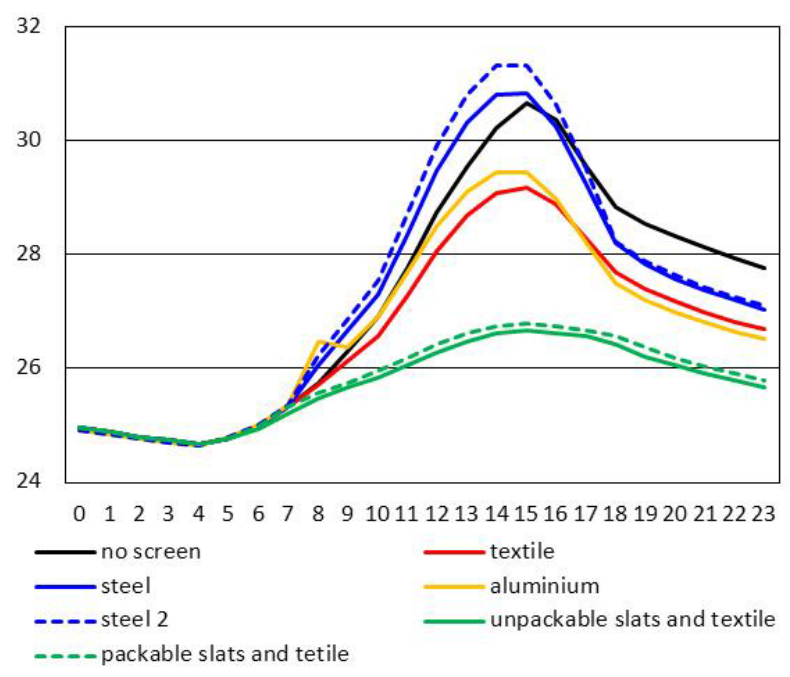

Fig. 15 July 21st, room MRT values $\left[{ }^{\circ} \mathrm{C}\right]$. 
The two kinds of steel screens are both characterised by an area-averaged solar absorption coefficient value (0.343) higher than the ones of the other screens, because of the darker colour. Furthermore, the steel screen polished on the external side reaches the highest temperatures, because of lower IR heat losses towards the window. Thus, because of their high emissivity in the internal side and the high temperatures reached, steel screens heat up internal surfaces at higher temperatures.

Figs. 14 and 15 show mean radiant temperature (MRT) values obtained with different screens in a winter day and in a summer day; the consequences on the thermal comfort are analysed in subsection 5.3.

In all the following diagrams, the behaviour of various screens in absence of external slats and the behaviour of two types of external inclinable slats combined with the internal textile screen are represented, with the aim to quantify the advantage of the external devices with respect to internal screens.

\subsection{Energy Performance}

The examined room is characterized by high internal heat gains, thus heating loads are present only for short winter periods. Therefore, the screen attitude to reduce solar gains is helpful for the most of the time in the year, while it hampers the effective exploitation of useful solar heat gains only in the short winter periods in which heating loads are present.

Therefore, the textile screen is the most convenient. This kind of diffuser would be the most convenient in winter too, in presence of higher internal heat gains: four occupants rather than two, for instance, or lower thermal losses due to a less extended glazed surface.

As regards the energy performance, the textile screen is followed by the aluminium one. Obviously, the worst energy performance is the one related to the steel screens, which provide the higher heat gains all over the year.

The most efficient screen, i.e. the textile one, has been compared against two configurations including both the same textile screen and an additional external tiltable slats array with diffusing surfaces. Two kinds of slats have been considered: packable and non packable. Their total reflection coefficient is equal to 0.6 (for both sides), both in the total solar spectrum and in the visible spectrum. In a previous work [2], this last kind of device was acknowledged as the most convenient among similar external devices, if controlled by a "seasonal logic".

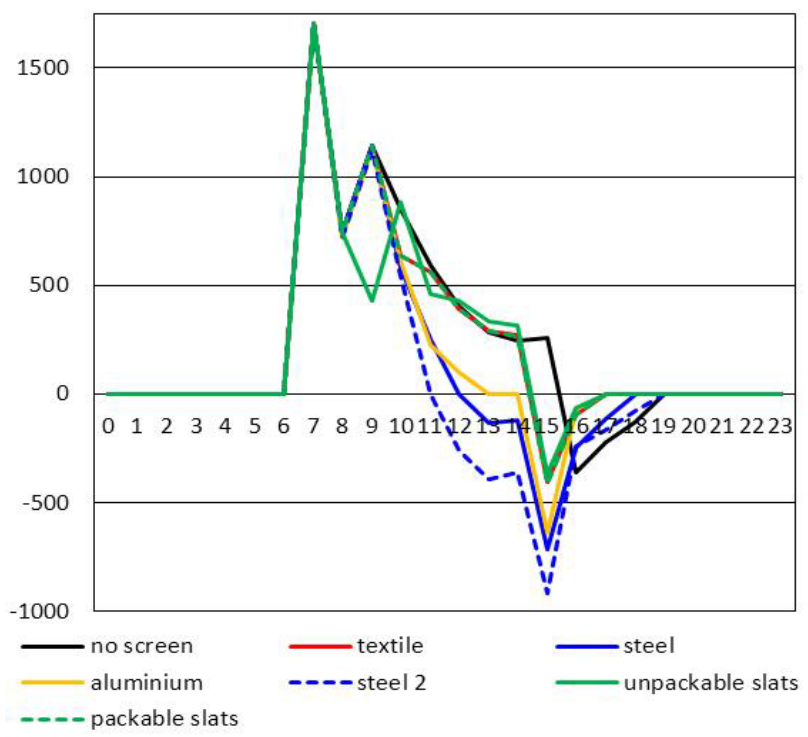

Fig. 16 January 21st, system thermal load with different screens [W]

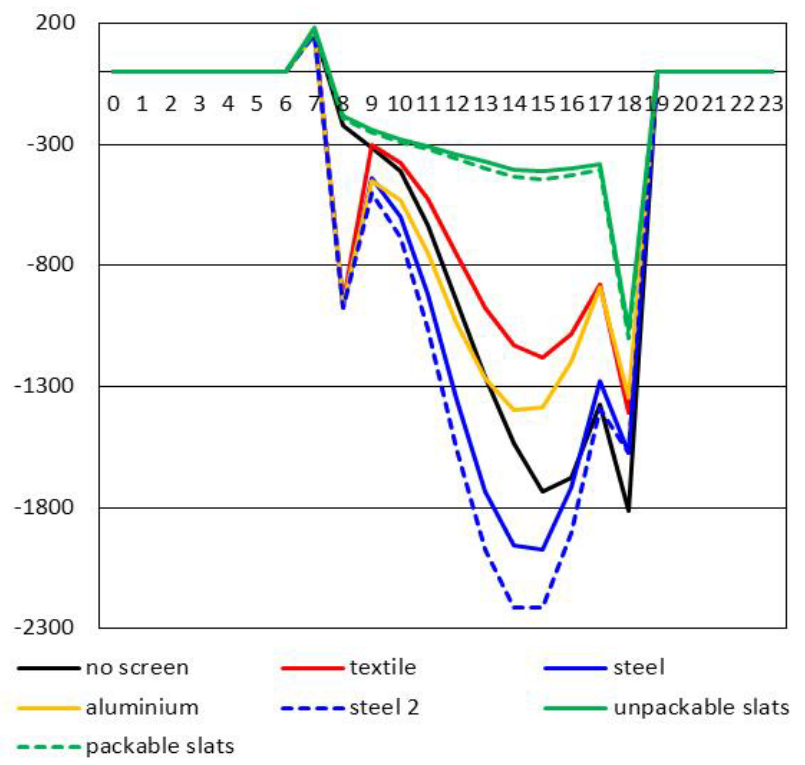

Fig. 17 July 21st, system thermal load with different screens $[\mathrm{W}]$ 


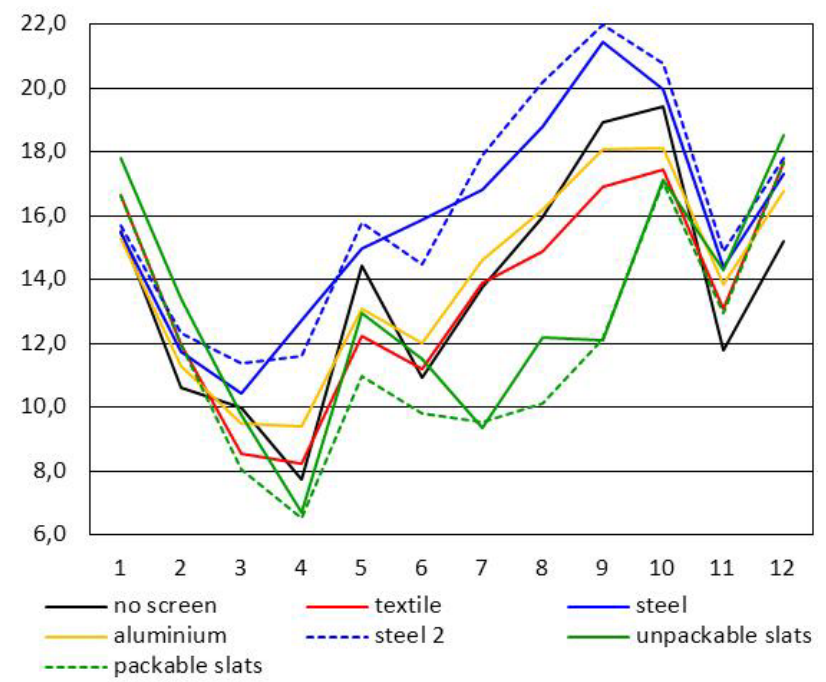

Fig. 18 Monthly primary energy demand for HVAC and lighting with different kinds of screen $\left[\mathrm{kWh} /\left(\mathrm{m}_{\text {floor }}^{2} \cdot\right.\right.$ month $\left.)\right]$

This control logic can be described as follows: in each moment, slats are inclined at an angle that allows the entrance of the only solar energy fraction that can contribute to cover the sensible thermal load, and avoiding overheating.

In the winter, a not-packable array of external slats, although aligned with the sunrays, reduces the diffuse part of the available solar radiation and indoor daylighting, with consequent larger use of artificial lighting. This problem lowers sensibly the related savings.

In the longer cooling period, external slats are more efficient to reduce unwanted solar gains and they are used as an alternative to internal screens, because they are tilted in order to intercept completely the direct radiation, thus avoiding glare phenomena. In this situation, they provide better indoor illuminance uniformity index values (around 0.8 instead of 0.6 in July) and better thermal comfort, because of the lower glazing inner surface temperature.

With an external packable array of slats, total annual primary energy demand for lighting and HVAC is about $12 \%$ lower, with a peak of savings around $30 \%$ in the period from July to September. If the array of slats is not packable, this device is less convenient when compared with the textile screen alone (the annual primary energy demand would be only $4.2 \%$ lower).

\subsection{Thermal Comfort}

For the reasons shown in subsection 4.1, the value of the indoor MRT is higher with screens reaching the highest temperature values, i.e. the two steel diffusers. As a matter of fact they are warmer and they heat up the other internal surfaces by radiation heat transfer.

In the coldest period, in the configurations equipped with steel screens, the MRT value is around $20^{\circ} \mathrm{C}$ only around midday (see Fig. 6), with positive effects on the PMV value, whose value approaches zero. With the other screens, the textile one in particular, the value of MRT is lower and PMV reaches negative values.

While during the largest part of the middle season MRT values ensure comfort conditions, during the warmer periods of the year the value of MRT is higher than the one recommended by the standards and the

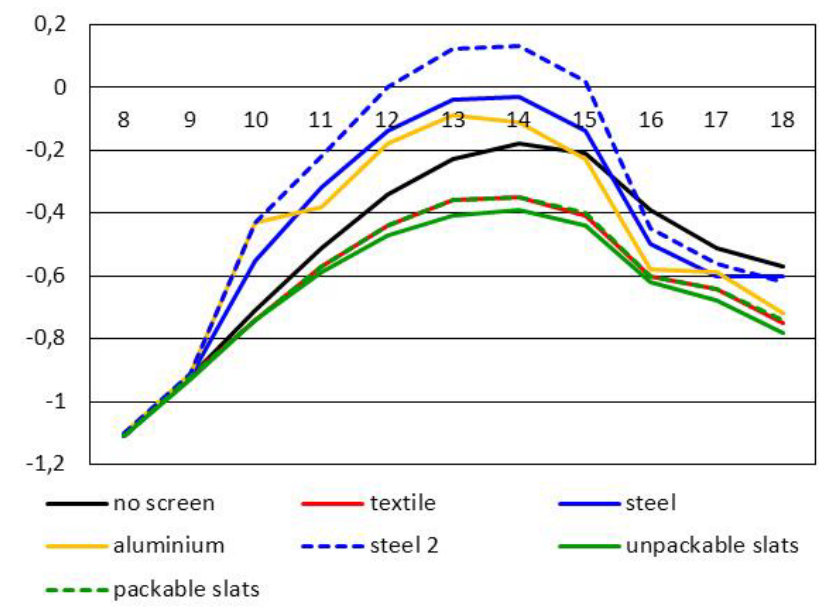

Fig. 19 January, 21th, spatial averaged PMV values.

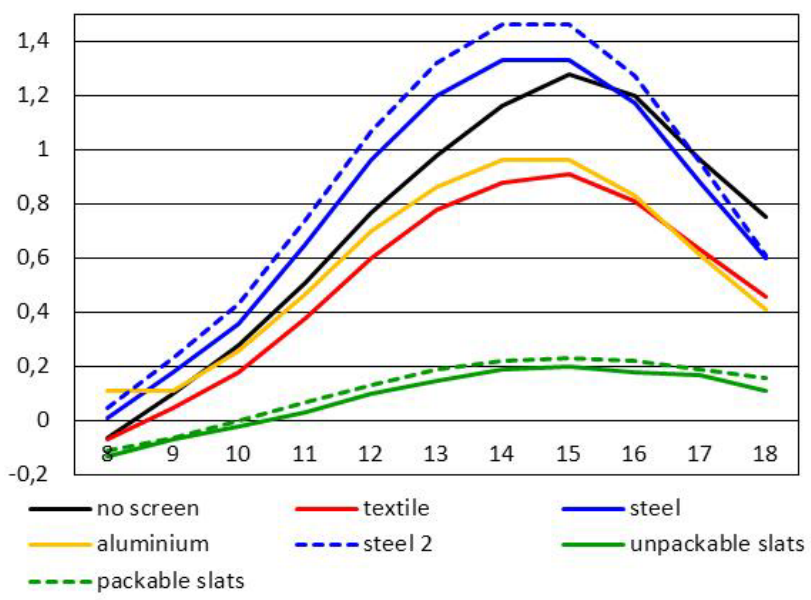

Fig. 20 July, 21th, spatial averaged PMV values. 
PMV value is consequently too high. In particular, in July the value of the temperature of externally polished steel screens may reach $40^{\circ} \mathrm{C}$, with related values of MRT and PMV equal to $30^{\circ} \mathrm{C}$ and +1.6 respectively, thus higher than in a room with no screen. In the same period, textile and aluminium screens allow PMV values to be limited between +0.8 and +0.85 .

The use of PMV and operative temperature as indoor environment control parameters have been explored too. This kind of controls would be energy efficient only in presence of steel screens and for a very limited period: i.e. the afternoons of the coldest period of the winter, when the MRT is higher than $20^{\circ} \mathrm{C}$ and PMV would be higher than zero if air temperature is set to $20^{\circ} \mathrm{C}$.

The period of convenience would be larger for rooms with a lower thermal inertia: in fact, in this case, the MRT would increase more significantly during the morning, and would require a lower indoor air temperature to achieve comfort conditions.

In the considered configuration, as shown in Fig. 21, the control on PMV would cause a total annual primary energy demand $11.1 \%$ higher than with usual room air thermostats. The minimum increase happens in February (near null) and the maximum in August $(+20.1 \%)$. Using a control on operative temperature $\left(t_{0}\right)$,

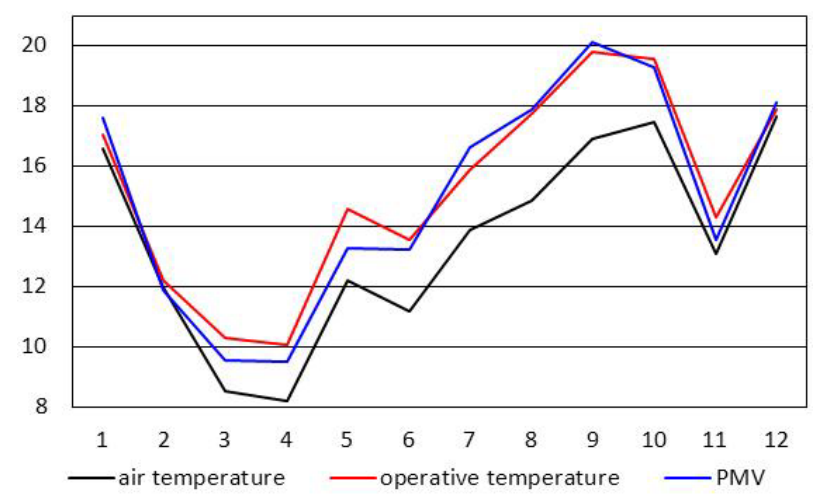

Fig. 21 Textile screen, monthly primary energy demand for HVAC and lighting with control on various indoor environment parameters: on internal air temperature (black line), on operative temperature (red line) and on PMV (blue line) $\left[\mathrm{kWh} /\left(\mathrm{m}_{\text {floor }}^{2} \cdot \mathrm{month}\right)\right]$. the total annual primary energy demand would be $12.5 \%$ higher.

\subsection{Plane Radiant Temperature Asymmetry}

Usually, in this kind of buildings, the horizontal plane radiant temperature (tpr) asymmetry is due to the cold glazed surface, but, in presence of internal screens, this asymmetry may assume opposite direction because of the warm screen surface. Hence, its value is higher for occupants closer to the screen. The value of tpr asymmetry is generally close to zero in case of textile diffuser, whereas it is within $3 \mathrm{~K}$ with aluminium and steel screens. In case of externally polished steel screens, this parameter reaches the value of $4 \mathrm{~K}$ in January and $5 \mathrm{~K}$ in July. The vertical asymmetry is generally low. In all the cases, asymmetry values are below the limits recommended by Italian standards: 10 $\mathrm{K}$ for horizontal asymmetry and $5 \mathrm{~K}$ for the vertical one.

\subsection{Design Advises}

The simulation results show that, when heating loads are dominant, ideal screen requirements would consist of low emissivity and high solar absorption coefficient (dark color) on the external side, and high emissivity and clear color on the internal side. On the contrary, when cooling loads are dominant, the screen should present opposite characteristics: low emissivity on the internal side, high emissivity on the external face, clear color on both sides.

A simulation about a textile screen with low emissivity internal coating was performed too. The consequent results show that, at least in this case study, it is not convenient to have a low emissivity value on the internal side. This quality reduces IR thermal exchanges between the screen and internal surfaces, whose temperatures decrease of about $0.14 \mathrm{~K}$, whereas the temperature of the screen becomes about $1 \mathrm{~K}$ higher. Consequently, the value of the MRT is about $0.1 \mathrm{~K}$ higher, and the cooling loads are around $8 \%$ higher too. However, the results can be different in a room characterized by a different geometry, in particular 
depending on the area of the glazed surface.

An internal device varying its own characteristics depending on the presence of heating or cooling demand would ensure the maximum energy efficiency, indeed. This may be achieved by the alternate use of two different screens or a double-face rotating screen.

\subsection{Considerations about Lighting System Typology}

All the results shown above are related to a usual lighting system, but a more efficient system can modify them relevantly. Therefore the results compared with the ones relating to three other lighting systems:

- a system constituted by the same fluorescent lamps but split into two zones, one closer to the window and the other further,

- a system consisting of LED lamps with the same luminous efficiency as the previously described fluorescent lamps and in which the luminous flow is controlled by dimmers,

- a LED system split into two zones, and controlled by dimmers.

The simulation results show that the highest energy saving is achievable by using the dimmer. The additional convenience given by zoning is small, because it concerns an already reduced luminous flux.

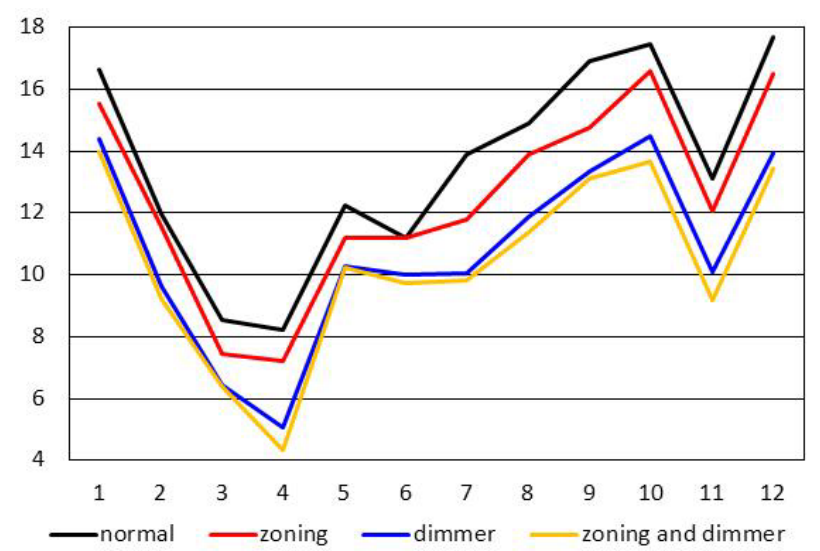

Fig. 22 Textile screen, monthly primary energy demand for HVAC and lighting with various kinds of lighting systems: normal (black line), split into two zones (red line), equipped by dimmer (blue line) and with the combined effect of zoning and dimmer (yellow line) $\left[\mathrm{kWh} /\left(\mathrm{m}_{\text {floor }}^{2} \cdot \mathrm{month}\right)\right]$.

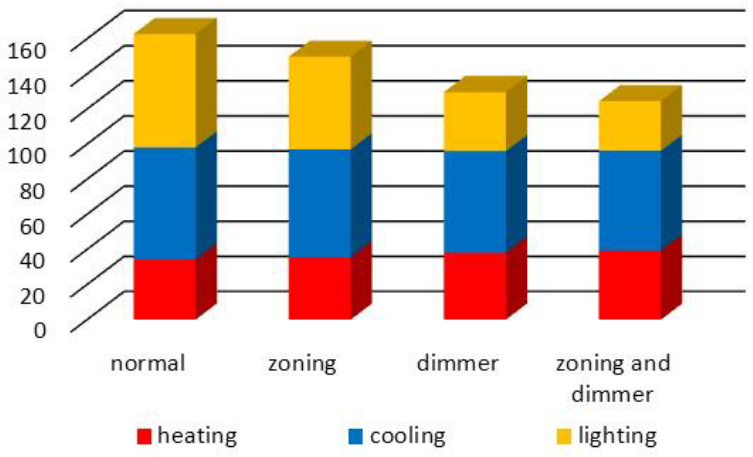

Fig. 23 Textile screen, annual primary energy demand for HVAC and lighting with various kinds of lighting systems $\left[\mathrm{kWh} /\left(\mathrm{m}_{\text {floor }}^{2}\right.\right.$ year $\left.)\right]$.

In particular, the results obtained by simulating the use of zoning and dimmer show that the annual primary energy demand for HVAC decreases with decreasing of lamps consumption, but in a short extent. Therefore, over $90 \%$ of the energy saving is due to the reduction of the energy used by the lamps.

Indeed, the differences in the HVAC energy demand should be higher in the heating period, when lamps are used over a longer period in the day. However, in this period the lower internal heat gains coming from lamps imply higher heating energy consumption in some periods of the day, almost compensating the savings in cooling energy achieved in other periods of the same day. In the cooling period, instead, the lamps are used only for a short time and savings due to the lower heat gain are not relevant. With different occupancy profiles (e.g., prolonged in the evening), the effects could be very different.

\section{Conclusions}

The simulation results show that in the investigated case study an internal screen transmitting less thermal energy towards the indoor environment ensures the best energy efficiency as well as the best thermal comfort.

The most energy efficient screen among the ones considered, i.e., the textile one, shows a performance similar to the one of an external packable array of tiltable slats. 
Anyway, to achieve the best performance, it would be convenient to combine external and internal devices in the same glazed building component. The performance would be further improved by using an indoor curtain able to change its own thermal characteristics depending on the thermal load. Such a result can be obtained with the alternate use of two different screens or a double-face rotating screen.

\section{References}

[1] A. Carbonari, Thermal and Luminous Comfort in Classrooms: A computer method to evaluate different solar control devices and its operating logics, in: Proceedings of PLEA 2012 - The 28rd Conference, Opportunities, Limits \& Needs Towards an Environmentally Responsible Architecture, Lima, Perù, 7-9 November 2012, Pontificia Universidad Católica del Perú.

[2] A. Carbonari, Energy demand, thermal and luminous comfort in office buildings: A computer method to evaluate different Solar Control Strategies, in: Proceedings of PLEA 2014 - The 30rd International PLEA Conference, Sustainable Habitat for Developing Societies-Choosing the Way Forward, Ahmedabad, India, 16-18 December 2014, Vol. I, Centre for Environmental Planning and Technology (CEPT), India.

[3] P. O. Fanger, Thermal Comfort, New York: Mc Graw-Hill, 1970.
[4] UNI EN ISO 7730, Determinazione degli indici PMV e PPD e specifica delle condizioni di benessere termico, Settembre 1997.

[5] R. Lazzarin, Sistemi solari attivi, manuale di calcolo, in: F. Muzzio \& C. Padova (Eds.), Solar Passive Systems: A Calculation Handbook, 1981.

[6] M. Collares-Pereira and A. Rabl, The average distribution of solar radiation: Correlations between diffuse and hemispherical and between daily and hourly isolation values, Solar Energy 22 (1979) 155.

[7] M. Cucumo, D. Kaliakatzos, V. Marinelli and M. D. Vivacqua, Metodi di calcolo della luminanza del cielo e dell'illuminamento naturale su superfici esterne (Calculation methods of sky luminance and daylighting of external surfaces), Condizionamento dell'Aria Riscaldamento Refrigerazione 5 (1997) 485-496.

[8] R. G. Hopkinson, P. Petherbridge and J. Longmore, Daylighting, Heinemann, London, 1963.

[9] CIE (Commission Internationale de l'Eclairage). Discomfort glare in interior lighting, Pubblicazione 117 (1995).

[10] T. Poli, A. G. Mainini, R. Paolini, A. Speroni, L. Vercesi, and M. Zinzi, Sviluppo di materiali e tecnologie per la riduzione degli effetti della radiazione solare. A. implementazione delle prestazioni e nuovi prodotti per il controllo della radiazione solare e costruzione di un archivio cartaceo di prodotti innovative, Ricerca di Sistema Elettrico, ENEA-MINISTERO DELLO SVILUPPO ECONOMICO, 2013. 